\title{
Implications of Behavioral Economics for Law Making
}

\author{
Ms. MeghnaDangi ${ }^{1}$, Dr. Ravi Vaidya ${ }^{2}$ \\ '(Auro University, Surat, India) \\ ${ }^{2}$ (S.R. Luthra Institute of Management, Surat, India)
}

\begin{abstract}
Economics as a body of knowledge has been known to have an immense impact on the analysis and practice of Law and Law making. In fact, various economic tools to analyze law are taught in law schools and used by law makers to shape law. The basic assumption from which all economic analyses starts is that individuals are rational and take actions to maximize their utility. However there have been some noneconomists who have not bought this assumption. This has given birth to a new school of thought known as Behavioral Economics. These experts believe that individuals are "normal" rather than "rational". According to this school of thought, individuals make choices based on limited information and limited cognitive ability and therefore their choices are not the ones that will "maximize" but "satisfice" the utility.As a result, the behavior and reaction to changes in Law of these individuals subject to bounded rationality are different from behavior and reaction of rational individuals. Although research in this area is becoming popular, the relationship between law and behavioral economics is still at its incipient stage.

This is a conceptual and by and large a descriptive paper which attempts to provoke a thought in the mind of the reader that behavioral economics may be a more appropriate approach to analyze and shape Law. Its purpose is to extract from literature what behavioral economics is about and then consider some implications of behavioral economics for lawmaking. The authors feel that an endeavor to understand this relationship will help the lawmakers in ensuring that resources flow to their highest valued use.
\end{abstract}

Key words:Behavioral Economics, Bounded Rationality, Lawmaking

\section{Introduction}

This Research offers a broad vision of how law and economics analysis may be improved by increased attention to insights about actual human behavior. By drawing attention to cognitive and motivational problems of both citizens and government, behavioral economics and law offer answers distinct from those offered by the standard analysis. The goal of this article is to advance an approach to the economic analysisof law that is informed by a more accurate conception of choice, one thatreflects a better understanding of human behavior and its origins. An attempt is made to touch on a wide range of issues in an effort to show the potentialuses of behavioral insights. The unifying idea in the analysis is that behavioraleconomics not only shows the path to model and predict behavior relevant to law withthe tools of traditional economic analysis, but with more accurate assumptionsabout human behavior, one can make more accurate predictions and prescriptionsabout law. An approach based on behavioral economics will helpwith the three functions of any proposed approach to law: positive, prescriptive, and normative.

The positive task, perhaps most central to economicanalysis of law and our principal emphasis here, is to explain both the effectsand content of law. How will law affect human behavior? What will be individuals'likely response to changes in the rules? Why does law take theform that it does? A superior understanding of human behavior will improveanswers to such questions. Also, Positive work isconcerned with predictions. If, contrary to conventional assumptions, people dislike losses far more than they like equivalent gains, predictions will go wrong insofar as they rest on conventional assumptions.

The prescriptive task is to see how law might be used to achieve specifiedends, such as deterring socially undesirable behavior. Prescriptive work is concerned with showing how society might actually reach shared goals which in itself is a central purpose of economic analysis of law.

The normative task is to assess more broadly the ends of the legal system. Normative work is concerned with what the legal system should do. If, for example, people use heuristic devices that lead to systematic errors, their judgments about how to deal with risks may be badly misconceived. If people are unrealistically optimistic, they may run risks because of a factuallyfalse belief in their own relative immunity from harm, even if they are fully aware of the statistical facts. And if people's choices are based on incorrect judgments about their experience after choice, there is reason to question whether respect for choices, rooted in those incorrect judgments, is a good way to promote utility or welfare. This in depth understanding will ultimately lead to possible improvement of the legal system. 


\section{Review of Literature}

The history of the economic analysis of law dates back to the criminal lawtheories of Bentham and Beccaria, which reflected the view that threatened legal sanctions canbe used to discourage socially undesirable conduct. Surprisingly, this view of law as creatingincentives for behavior seems not to have been revived again until the 1960s with the work ofCoase (1960), Calabresi (1961), and Becker (1968), among others. Much of this early work was rather informal in that it did notemploy mathematical models. Still, the insights it offered set that stage for the next generationof formal economic analysis. The first use of mathematics to model law was apparently by a judge, LearnedHand, in the well-known tort case of U.S. v. Carroll Towing. In that case, Judge Hand put forthhis famous "Hand rule" for determining negligence, which says that an injurer should be foundnegligent if $B<P L$, where $B$ is the burden (or cost) of care sufficient to eliminate the risk of anaccident, $P$ is the probability of an accident if no care is taken, and $L$ is the loss from theaccident. This simple formula, when properly interpreted in its marginal form (Posner, 1972), turns out to give exactly the right answer regarding when care is efficient. This was formallydemonstrated by Brown (1973), whose "model of precaution" has become the standardframework for examining the efficiency of various liability rules. One of the most important insights that emerged from Brown's formalization is that anegligence rule can simultaneously induce both injurers and victims to invest in efficientprecaution. Establishing this result, which provides an economic justification for thepredominance of negligence law throughout the twentieth century, likely would nothave been possible without formal modeling because it required the derivation of a Nashequilibrium in a two person, non-cooperative game setting. Cooter (1985) went on to show thatthe insights from the model of precaution can be extended beyond tort law to illuminatedoctrines in contracts and property as well. Thus, the simple approach first employed by JudgeHand to decide a specific case in tort law has been used by economists to develop a coherentframework for understanding large areas of the common law, thereby illustrating the unifyingpower of economic models.

This unity extends to criminal law as well, as illustrated by Becker's (1968) formalizationof the ideas of Bentham and Beccaria. After all, criminal law, like tort law, is primarily aboutpreventing unwanted harm, and to that end Becker interpreted criminal sanctions, whether in theform of fines or prison, as functioning like liability to attach a "price" to harmful behavior. Inparticular, if $H$ is the harm caused by a criminal act, then optimal deterrence requires that theexpected sanction, $P S$, be set equal to $H$ (or $P S=H$ ), where $P$ is the probability that the offenderis caught and convicted, and $S$ is the sanction. One of the central insights arising from this perspective is that it does not matter whether the harm is intentionally or accidentally imposed;as long as the sanction (or liability) is appropriately set, the would-be criminal (injurer) willoptimally refrain from the harmful act. (In this sense, there is no obvious theoretical reason toseparate criminal and tort law, an insight that has spawned a large literature-see, for example,

Friedman (2000) Nor does it matter if the sanction is imposed with certainty; aslong as it is appropriately scaled to reflect uncertain enforcement - that is, as long as theexpected sanction is properly set-it will have the desired effect on behavior.

The contribution by Landeo, Niktkin, and Izmalkov uses behavioral economics to study tortlitigation, but their focus is how "self-serving bias"- the belief by litigants that the court willfavor their positioninfluences litigation and incentives for care. Although there is considerable

experimental evidence for such a bias, little theoretical work exists on this issue, other than the early“differing perceptions" models of pre-trial bargaining by Landes (1971) and Gould (1973), which attributed trials to the existence of "mutual optimism" by plaintiffs and defendants aboutthe outcome of a trial.

The law and economics movement applies economic theory and method to the practice of law. It asserts that the tools of economic reasoning offer the best possibility for justified and consistent legal practice. It is arguably one of the dominant theories of jurisprudence. The law and economics movement offers a general theory of law as well as conceptual tools for the clarification and improvement of its practices. The general theory is that law is best viewed as a social tool that promotes economic efficiency, that economic analysis and efficiency as an ideal can guide legal practice. It also considers how legislation should be used to improve market conditions in return. Law and economics offers a framework with which to model legal outcomes, and common objectives with which to unify disparate areas of legal activity. The bringing together of legal theory and economic reasoning has also created new research agendas in the fields of behavioral economics: how rationality affects people's behavior within legal scenarios; public choice theory and how collective behavior should have an effect on legislation; and game theory: understanding strategic action in a legal context.

\section{What is Behavioral Economics}

In order to identify, in a general way, the defining features of behavioraleconomics, it is useful first to understand the commonality between law and economics. This approach to the law posits thatlegal rules are best analyzed and understood in light of standard economicprinciples. Gary Becker offers a typical account of those principles: "Allhuman behavior can be viewed as involving participants who [1] maximizetheir utility [2] from a 
stable set of preferences and [3] accumulate an optimalamount of information and other inputs in a variety of markets." Thetask of law and economics is to determine the implications of such rationalmaximizing behavior in and out of markets, and its legal implications formarkets and other institutions. Although some of Becker's particular applicationsof the economic approach might be thought of as contentious, thatgeneral approach underlies a wide range of work in the economic analysis oflaw. The task of behavioral economics and law is to explorethe implications of actualhuman behavior for the law.

There are three important limits or "bounds" on human behavior,bounds that draw into question the central ideas of utility maximization, stablepreferences, rational expectations, and optimal processing of information.

People can be said to display bounded rationality, bounded willpower, andbounded self-interest.All three bounds are well documented in the literature of other social sciences,but they are relatively unexplored in economics. Each of these bounds representsa significant way in which most people depart from the standard economic model.

\section{Bounded Rationality, bounded willpower, and bounded self-interest}

In economics, man or "Homo economicus" appears perfectly rational and has a complete knowledge and his economic choices are guided by rationality. This means that his choices are consistent, self-contained and he is perfectly rational without being affected by his emotions or his environment. However, as per studies conducted by Herbert Simon, rationality of individuals is limited by the information they have, the cognitive limitations of their minds and the finite amount of time they have to make decisions. He has coined the term "bounded rationality" in Models of Man (1957). He argues that most people are only partly rational while are emotional/irrational in the remaining part of their actions. He says that perfect or global rationality is practically and not logically impossible. He claims that classical theories of Rational Choice fail to include some of the central problem of conflict and dynamics which economics are more and more concerned with. Accordingly, concept of rationality has some limits such as risk and uncertainty, incomplete information about alternatives and complexity. (Models of Man,1972). So for a proper description of process of choice in economics, psychological theory is very important. Thus, since individuals lack the ability and resources to arrive at the optimal solution, they instead apply their rationality only after having greatly simplified the choices available. As a result, Simon claims that individuals have only bounded rationality and are forced to make decisions not by 'maximization' but by 'satisficing'. Satisficing is the hypothesis which allows to the conception of diverse decision procedures and which permits rationality to operate in an open not pre-determined space (Barros, 2010). In the real world, individuals make decisions using heuristics or rules of thumb that satisfice rather than maximize utility over the long run. Thus individuals employ the use of heuristics to make decisions rather than a strict rule of optimization

Bounded rationality, an idea first introduced by Herbert Simon, refers tothe obvious fact that human cognitive abilities are not infinite.Human beings havelimited computational skills and seriously flawed memories. To deal with limited memories we make lists. To deal with limited brain power and time we use mental shortcuts and rulesof thumb. Because of this, human behavior differs in systematic ways from that predicted bythe standard economic model of unbounded rationality and such behavior is the cause behind predictable mistakes. A major source of differences between actual judgments and unbiasedforecasts is the use of rules of thumb or "heuristics" as discussed by Daniel Kahneman and Amos Tversky in their path breaking work.

People display bounded rationality: They suffer from certainbiases, such as overoptimism and selfserving conceptions of fairness; theyfollow heuristics, such as availability, that lead to mistakes; and they behavein accordance with prospect theory (Tversky and Kahneman, 1979) rather than expected utility theory. Bounded rationality means that information is not processed according to a model of perfect means-end rationality but, on the contrary, is distorted due to limits of our cognitive abilities. For instance the endowment effect is thought to be a behavioral limit that distorts the proper valuation of property, an important aspect of bargaining to efficient outcomes.

Another claim is that our cognitive abilities are distorted by the availability heuristic. According to this the availability of strong imagery may induce us to over or underestimate the actual probability of events associated with the image. For instance, graphic representations of highly improbable harms might be more influential on behavior and demand unjustified use of resources than statistical analysis showing another equally undesirable harm to be more common and easier to avoid. Jurisprudential practices could be significantly influenced by such results. For instance, judges might be as irrationally influenced by the availability heuristic as other human beings. Therefore victim impact statements might be important correctives to proceedings if a well-presented defendant's presence in the court skews judge or jury's decisions. An awareness of such a cognitive failure could help adjust legal reasoning and its conclusions accordingly. Hence we can infer that an 
awareness and exploitation of universal cognitive limits might help legislators to design more effective laws (Sunstein 2000).

In addition to bounded rationality, people often display bounded willpower. This term refers to the fact that human beings often take actions thatthey know to be in conflict with their own long-term interests. It simply means to eliminate anytemptation to succumb to the desire for immediate rewards. Thus, the demandfor and supply of law may reflect people's understanding of their own(or others') bounded willpower) Peoplealso have bounded willpower; they can be tempted and are sometimesmyopic.

Bounded self-interest is a term used to refer to an importantfact about the utility function of most people: They care, or act as if theycare, about others, even strangers, in some circumstances. In many market andbargaining settings people care about being treated fairly and want to treat others fairly ifthose others are themselves behaving fairly. As a result of these concerns, the agents in a behavioral economic model are both nicer and (when they arenot treated fairly) more spiteful than the agents postulated by neoclassicaltheory. People are boundedly self-interested. They are concerned about the wellbeingof others, even strangers in some circumstances, and this concern andtheir self-conception can lead them in the direction of cooperation at the expenseof their material self-interest

\section{Implications on Law Making}

Bounded rationality as it relates to judgment behavior will comeinto play whenever actors in the legal system are called upon to assess theprobability of an uncertain event. Example: Environmental Legislation, Negligence determination and risk assessment. Bounded rationality as it relates to decision making behavior will come into playwhenever actors are valuing outcomes; a prominent example here is lossaversion and its corollary, the endowment effect, which we discuss in connectionwith bargaining behavior, mandatory contract terms , prior restraints on speech, and risk assessments

Bounded willpower is most relevant when decisions have consequences overtime; our example is criminal behavior where the benefits aregenerally immediate and the costs deferred.

Finally, bounded self-interest is relevant primarily in situations in which one party hasdeviated substantially from the usual or ordinary conduct under the circumstances; in such circumstances the other party will often be willing to incurfinancial costs to punish the "unfair" behavior.Consider the positive relation between risk and return in financial markets. Aspredicted by this theory, stocks (equities) earn higher returns (on average)than do riskless assets such as treasury bills. But what can we say about themagnitude? Is this difference in return roughly what the theory would predict?

This is precisely the question posed by RajnishMehra and EdwardPrescott in their well-known paper on the "equity premium puzzle." Theequity premium is the difference in returns between equities and riskless assets.In the United States, the equity premium has been roughly six percentper year over the past seventy years. This implies that a dollar invested instocks in 1926 would, at the end of 1997 , be worth over $\$ 1800$, while a dollarinvested in treasury bills would have accumulated to less than $\$ 15$. Thisdifference is remarkably large. Mehra and Prescott therefore ask whether itcan possibly be explained by investor risk aversion. They conclude that itcannot. That is, no plausible value of risk aversion could explain such a bigdifference. Although the theory gets the sign right in this case, the magnitudeof the effect suggests that the theory is wrong.

\section{Reasons why adding behavioral variables on economic models will Result in better Law making:}

Some of the predictions of the standard model are simply wrong. Forexample, people can be both more spiteful and more cooperative thantraditional analysis predicts, and this matters a great deal to law. It isalso important to know that even in a world without transaction costs andwealth effects, the assignment of property rights alters the ultimate allocationof those rights, and that this may be particularly true for certainforms of property-rights assignment (such as court orders). These featuresof the world matter greatly for making predictions and formulatingpolicy.

In other cases economics makes no predictions (or incorrect predictionsof no effect). Prominent in this category are the effects of presentation;since economic theory assumes that choices are invariant to the mannerin which a problem is framed, it falsely predicts that the language of amedia account or advertisement has no effect on behavior, holding theinformation content constant. In contrast, it is well established that peoplereact differently to potential outcomes depending on whether they areperceived as foregone gains or outof-pocket costs (losses), and that theyare likely to think, mistakenly, that salient events are more common thanequally prevalent but more subtle ones. These points bear on the supplyof and the demand for law, and on the behavior of agents in their interactionswith the legal system.

Standard economic theories of the content of law are based on an undulylimited range of potential explanations, namely optimal or second-bestrules set by judges and rent-seeking legislation determined by 
selfinterestedlog-rolling. Behavioral economics offers other sources of potentialexplanation-most prominently, perceptions of fairness.

A behavioral approach to law offers a host of novel prescriptionsregarding how to make the legal system work better. Somestem from the improved predictions. Cognitivedifficulties and motivational distortions undermine or alter conventionaleconomic prescriptions about the jury's role, most notably in thecontext of assessing negligence and making other determinations of factor law.

Last but not the least, a behavioral approach to law and economics produces new questions about possible mistakes by private and public actors. On the one hand, itraises serious doubts about the reflexive antipaternalism of some economicanalysis of law. On the other hand, it raises equivalent questions about whether even well-motivated public officials will be able to offerappropriate responses to private mistakes and confusion.

\section{Conclusion}

Behavioral economics is a form of economics, and our goal is to strengthen thepredictive and analytic power of law and economics. Behavioral economics does not suggest that behavior is random or impossible to predict; rather it suggests, with economics, that behavior is systematic and can be modeled.

Behavioral economics, as I see it, is to take thecore insights and successes of economics and build upon them by makingmore realistic assumptions about human behavior. This paper suggestsretaining thepower of the economist's approach to social science while offering a betterdescription of the behavior of the agents in society and the economy. Behavioral economics and Law, in short, offers the potential to be law and economicswith a higher " $\mathrm{R}^{2 "}$ "- that is, greater power to explain the observeddata. This paper is an attempt to highlight some of that potential.

Further work could be done in the analytic and empirical fields to emphasize and explore the value and importance of the three bounds in the economic analysis of Law. Understanding of these implications will enrich conventional economic models by incorporating a more realistic conception of human behavior.

Future of economic analysis lies in better understanding of decision and choice. Although there is substantial scope for learning to override the influence cognitive distortions and understanding its implications on law making may take a long time, an endeavor in this direction will open new vistas in Law making. Let us hope that in the future, law makers will frame laws after incorporating useful findings of human behavior.

\section{References}

[1]. Becker, Gary S., "The economic approach to Human behavior", (1976), University of Chicago Press

[2]. Polinsky Mitchell A., "An introduction to Law and economics" (2003) $3{ }^{\text {rd }}$ Edition.

[3]. Available at SSRN: http://ssrn.com/abstract=413103 or http://dx.doi.org/10.2139/ssrn.413103

[4]. Posner, Richard A., "Economic Analysis of Law" (1988), $5^{\text {th }}$ Edition

[5]. Simon, Herbert A., "A behavioral model of Rational Choice”, (1955), 69 Q.J. ECON. 99

[6]. Amos Tversky\& Daniel Kahneman, "Judgment Under Uncertainty: Heuristics and Biases”, (1982), Cambridge University Press

[7]. Deborah M. Weiss, Paternalistic Pension Policy: Psychological Evidence and EconomicTheory, 58 U. CHI. L. REV. 1275 (1991).

[8]. RajnishMehra\& Edward C. Prescott, The Equity Premium: A Puzzle, 15 J. MONETARYECON. 145 (1985).

[9]. Jeremy J. Siegel \& Richard H. Thaler, Anomalies: The Equity Premium Puzzle, 11 J.

[10]. Friedman, David (2000) Law's Order: What Economics Has to Do with Law and Why it Matters, Princeton: Princeton Univ. Press.

[11]. Jolls, Christine; Sunstein, Cass R.; and Thaler, Richard, "A Behavioral Approach to Law and Economics" (1998).Faculty ScholarshipSeries.Paper 1765.

[12]. http://digitalcommons.law.yale.edu/fss_papers/1765 